Check for updates

The BMJ

kabbasi@bmj.com Follow Kamran on Twitter@KamranAbbasi Cite this as: BMJ 2021;374:n2268 http://dx.doi.org/10.1136/bmj.n2268 Published: 16 September 2021

\title{
The next step in immorality: charging to create and cure disease
}

\section{Kamran Abbasi executive editor}

Surrogate markers are seductive. In clinical trials and regulatory decisions, why not reach for something quick, convenient, and relatively cheap? Why stop patients receiving a treatment of plausible and potential benefit? That is the logic behind "accelerated pathways" for drug approval, such as the one used by the US Food and Drug Administration since the 1990s. But the FDA's experience is worrying, a story of claims unproved and obligations avoided (doi:10.1136/bmj.n2059). ${ }^{1}$ Surrogate markers rank with subgroup analyses, composite outcomes, and secondary outcomes as great deceivers in clinical trial design and reporting. Their overuse is a triumph of commercial hype, playing on the hope of a treatment that anybody with an illness will, understandably, cling to.

The promise of drugs approved on the basis of surrogate outcomes is mostly unsupported by trials and meta-analyses that use hard clinical outcomes, such as death and disease, even when the surrogate outcome is validated (doi:10.1136/bmj.n2191). ${ }^{2}$ Too often, in the regulatory setting, confirmatory trials with hard outcomes are not done or done too late, and patients continue to take drugs that are ineffective or harmful

(https://blogs.bmj.com/bmj/2021/og/15/surrogateendpoints-need-complementary-patient-reportedoutcomes). ${ }^{3}$ Germany's Institute for Quality and Efficiency in Healthcare, IQWiG, is rare in using strict criteria to limit recommendations that are based on surrogate outcomes, although the UK's National Institute for Health and Care Excellence is now seeking to tighten up its approval process (doi:10.1136/bmj.n2191). ${ }^{2}$

As with subgroup analyses, trials that rely on surrogate markers are generally best seen as hypothesis generating. An industry that reaps billions in profits argues that such trials make drug development affordable. But the industry's savings are picked up as costs by health services, possibly many times over, since prescribing ineffective and harmful drugs is expensive.

Such corporate manoeuvres affect the frontline of care, where overwhelming demand is being met by depleted resources. The new investment agreed for England's NHS will not tackle chronic workforce pressures, nor boost morale of beleaguered staff in primary care (doi:10.1136/bmj.n2236; doi:10.1136/bmj.n2224), ${ }^{45}$ nor deliver a better future for social care (doi:10.1136/bmj.n2242; doi:10.1136/bmj.n2227). ${ }^{67}$ Primary care will be stretched further by decisions to offer covid vaccinations to children aged 12-15 years (doi:10.1136/bmj.n2254;

https://blogs.bmj.com/bmj/2021/09/03/a-game-ofphone-tag-getting-children-of-clinically-vulnerableparents-vaccinated-has-been-disgracefully-chaot- ic), ${ }^{89}$ and booster doses to 30 million of the UK's most vulnerable adults (doi:10.1136/bmj.n2261). ${ }^{10}$ The "new normal" is already delivering more work, prompting media attacks (doi:10.1136/bmj.n2234), ${ }^{11}$ and promising “trouble ahead” (doi:10.1136/bmj.n2223). ${ }^{12}$

The next step in immorality is to charge patients to become sick and be paid to help with treatment. It's a step that Philip Morris International, one of the world's richest tobacco companies, is seeking to take with its proposed £1bn purchase of Vectura, a pharmaceutical company that makes inhalers for respiratory diseases (doi:10.1136/bmj.n2186). ${ }^{13}$ The question for healthcare organisations, including medical publishers, is whether they will treat Vectura as they do any other tobacco company. The BMJ, for its part, does not accept advertising or research published by tobacco companies, their foundations, or their wholly owned subsidiaries.

By contrast, we welcomed correspondence from a former archbishop of Canterbury. Rowan Williams wrote to The $B M J$ this week urging no change in the law on assisted dying (https://www.bmj.com/content/374/bmj.n2094/rr-1). ${ }^{14}$ British doctors' representatives, however, have voted by a narrow margin for the BMA to move to a neutral position (doi:10.1136/bmj.n2262) ${ }^{15}$-one that The BMJ supports. The moral arguments are complex, debate remains fierce, and the last decision by the BMA to adopt a neutral stance lasted only a year (doi:10.1136/bmj.333.7558.64). ${ }^{16}$

Lenzer J, Brownlee S. Should regulatory authorities approve drugs based on surrogate endpoints?BMJ 2021;374:n2059doi: 10.1136/bmj.n2059.

2 Dawoud D, Naci H, Ciani O, Bujkiewicz S. Raising the bar for using surrogate endpoints in drug regulation and health technology assessment. BMJ 2021;374:n2191doi: 10.1136/bmj.n2191.

3 Wilson R. Surrogate endpoints need complementary patient reported outcomes. BMJ Opinion. Sep 2021.

https://blogs.bmi.com/bmi/2021/09/15/surrogate-endpoints-need-complementary-patient-reported-outcomes.

4 Marshall M. Media attacks on GPs threaten the doctor-patient relationship. BMJ 2021;374:n2236. doi: 10.1136/bmj.n2236 pmid: 34521620

5 Gerada C. Clare Gerada: From clap to slap-general practice in crisis. BMJ 2021;374:n2224. doi: 10.1136/bmj.n2224 pmid: 34521647

6 Glasby J. Adult social care in England: more disappointment, delay, and distraction. BM/2021;374:n2242. doi: 10.1136/bmj.n2242 pmid: 34521644 Oliver D. David Oliver: What the plan for social care omitted. BMJ 2021;374:n2227. doi: 10.1136/bmj.n2227 pmid: 34507975

8 lacobucci G. Covid-19: Vaccinating children will help end pandemic, says minister. BMJ 2021;374:n2254. doi: 10.1136/bmi.n2254 pmid: 34521631

9 Davies M. "A game of phone tag" - getting children of clinically vulnerable parents vaccinated has been disgracefully chaotic. BMJ Opinion. Sep 2021. https://blogs.bmi.com/bmi/2021/09/03/a-game-of-phone-tag-gettingchildren-of-clinically-vulnerable-parents-vaccinated-has-been-disgracefullychaotic.

10 Wise J. Covid-19: Booster doses to be offered to 30 million people in UK. BM/2021;374:n2261. doi: 10.1136/bmi.n2261 pmid: 34521637

11 Mahase E. GPs are being blamed for government failures in primary care, say doctors. BM/2021;374:n2234. doi: 10.1136/bmj.n2234 pmid: 34518166

12 Salisbury H. Helen Salisbury: Trouble with the new normal. BMJ 2021;374:n2223. doi: 10.1136/bmj.n2223 pmid: 34521697

13 Agrawal S. Proposed takeover of Vectura by Phillip Morris International. BM/2021;374:n2186. doi: 10.1136/bmj.n2186 pmid: 34493597 
14 Williams RD. Re: There is nothing holy about agony: religious people and leaders support assisted dying too [rapid response]. BM/2021. https://www.bmj.com/content/374/bmj.n2094/rr-1.

15 lacobucci G. BMA moves to neutral position on assisted dying. BMJ2021;374:n2262. doi: 10.1136/bmj.n2262 pmid: 34521626

16 Kmietowicz Z. Doctors backtrack on assisted suicide. BMJ 2006;333:64.pmid: 16825229 